\title{
FORMAÇÃO CONTINUADA ONLINE DE PROFESSORES QUE ATUAM EM AMBIENTE HOSPITALAR: UMA ANÁLISE DAS DIFICULDADES PRESENTES NO PROCESSO FORMATIVO
}

\author{
Jacques de Lima Ferreira ${ }^{1}$ \\ Ygor Corrêa $^{2}$ \\ Marilda Aparecida Behrens ${ }^{3}$
}

\begin{abstract}
Resumo: Este artigo analisou as dificuldades enfrentadas por professores de diversos estados do Brasil, que atuam no ambiente hospitalar, quando do processo de ensino e aprendizagem destes em uma formação continuada Online. O aporte teórico apoia-se nas literaturas sobre Educação Online, Formação de Professores e Educação não Formal em ambiente hospitalar. Esta é uma pesquisa qualitativa que analisou 178 respostas de professores sobre as dificuldades encontradas durante a participação de um curso de extensão a distância. A análise dos dados foi realizada a partir da técnica de Análise de Conteúdo e com o auxílio do software Atlas Ti. Os resultados revelaram que a falta de tempo para realizar a formação deve-se ao excesso de atividades docentes, assim como a dificuldade para interagir como aluno Online são implicações vivenciadas neste processo formativo.
\end{abstract}

Palavras-chaves: Formação de Professores; Educação a Distância; Educação não Formal.

\section{CONTINUED ONLINE TEACHER TRAINING THAT WORK IN HOSPITAL ENVIRONMENT: AN ANALYSIS OF THE DIFFICULTIES PRESENT IN THE TRAINING PROCESS}

\begin{abstract}
This paper analyzed the difficulties faced by teachers from different states of Brazil, who work in hospital environment, in view of the teaching and learning process that participated of an Online continued education. The theoretical framework is based on the literature of Online Education, Teacher Training and Non-Formal Education in hospital environment. This is a qualitative research that analyzed 178 responses of teachers about the difficulties found out during the participation of a distance extension course. The data analysis was conducted using the Content Analysis technique with the support of Atlas Ti software. The results revealed that the lack of time to participate of the teacher training, due to the excess of teaching activities, as well as the difficulty to interact as Online student, are implications experienced in this training process.
\end{abstract}

Keywords: Teacher training; Distance Education; Non-Formal Education.

\footnotetext{
${ }^{1}$ Doutor em Educação - Universidade Positivo (UP) e Universidade Federal do Paraná (UFPR).

${ }^{2}$ Doutor em Informática na Educação - Centro Universitário Ritter dos Reis (UNIRITTER)

${ }^{3}$ Doutora em Educação - Pontifícia Universidade Católica do Paraná (PUCPR)
} 


\section{INTRODUÇÃO}

O campo de atuação profissional dos professores vai muito além da escola enquanto instituição, não limitando-se, na contemporaneidade, à sala de aula, a qual esse tem transcendido cada vez mais. Nesta perspectiva, o processo de ensino e aprendizagem apresenta-se de modo complexo e dinâmico, podendo ocorrer tanto no formato presencial, quanto a distância, seja por meio da modalidade de educação formal ou não formal.

Diante deste cenário, no que tange ao crescente progresso das Tecnologias da Informação e Comunicação (TIC), infere-se que esse possibilitou que o processo de formação de professores ocorra na modalidade da Educação a Distância, na formação inicial e continuada por meio da Educação Online. Esse formato de educação permite a profissionalização docente de muitos professores, que utilizam recursos tecnológicos e diversas mídias em diferentes contextos para ensinar e aprender. Atualmente, muitos professores atuam além dos muros da escola, educação essa denominada como educação não formal, que configura-se como um "conjunto de práticas socioculturais de aprendizagem e de produção de saberes, que envolve organizações/instituições, atividades, meios e formas variadas, assim como uma multiplicidade de programas e projetos sociais" (GOHN, 2010, p. 33). A profissionalidade docente no contexto da educação não formal pode ocorrer em hospitais, organizações não governamentais (ONGs), presídios, empresas, entre vários outros contextos, diante da necessidade social.

Neste horizonte, o presente estudo investiga a formação continuada Online de professores atuantes em ambiente hospitalar, com vistas a analisar as dificuldades enfrentadas por estes durante a realização de um curso via Educação a Distância. Esta pesquisa foca-se, especificamente, nas dificuldades encontradas pelos professores, tendo em vista a dinâmica cotidiana desses profissionais, que dão continuidade ao processo de escolarização de alunos que encontram-se internados em hospitais para tratamento médico prolongado. Deste modo, infere-se que o desafio em relação à formação continuada, no caso de professores que atuam em contexto de educação não formal, neste caso, hospitais, reside em organizar-se de modo a contemplar a jornada de trabalho, que não se configura de modo clássico, como em uma escola ou universidade, e o tempo de dedicação a um curso em Educação a Distância. Convém observar que o 
estudo não se dedica à descrição da atividade docente em hospitais, mas sim às dificuldades do processo formativo Online.

Para fins de análise e compreensão do objeto de estudo desta pesquisa, adota-se as postulações teóricas de pesquisadores como Kearsley (2011), Santos (2009) e Silva (2009, 2012) para a Educação Online no processo de formação de professores, assim como a partir da perspectiva de Ferreira e Behrens (2016), Ferreira e Matos (2015) e Ferreira (2013) para a formação de professores no ambiente hospitalar. Para tanto, esta é uma pesquisa qualitativa do tipo exploratória de natureza interpretativa, que contou com a participação de 178 professores de diversos estados brasileiros, que atuam em ambiente hospitalar, os quais responderam um questionário Online ao participarem de um curso de extensão Online. O curso em questão foi aprovado pelo Conselho Nacional de Desenvolvimento Científico e Tecnológico (CNPq) e intitulado como "Eureka Ambiente Virtual favorecendo a formação continuada Online para professores que atuam com escolares hospitalizados", via ambiente virtual de aprendizagem (AVA) Eureka da Pontifícia Universidade Católica do Paraná (PUCPR).

A análise dos dados coletados por meio do questionário Online foi realizada com o auxílio do software Atlas Ti, assim como a partir da Análise de Conteúdo (AC) proposta por Bardin (2011). Considera-se que os achados científicos provenientes deste estudo possam contribuir para o campo da formação continuada Online de professores atuantes em ambiente hospitalar, de maneira a colaborar com o desenvolvimento de futuros processos formativos, destinados a professores que lecionam em hospitais. Não obstante, o formato de educação não formal realizado em hospitais carece de aprofundamentos científicos, especialmente, em se tratando da participação de professores em cursos online, que sejam condizentes à realidade destes profissionais da Educação. O presente artigo está dividido em Educação Online no processo de Formação de Professores; Educação não Formal no ambiente Hospitalar; Metodologia; Análise de Dados e Resultados; Considerações Finais e Referências. A seguir, apresenta-se o entendimento que se tem sobre a Educação a Distância no formato Online e suas implicações no processo de formação de professores.

\section{EDUCAÇÃO ONLINE NO PROCESSO DE FORMAÇÃO DE PROFESSORES}

O progresso tecnológico afeta significativamente a vida em sociedade e, consequentemente, influencia a educação, a forma de ensinar e aprender e a formação 
dos professores. As tecnologias da informação e comunicação (TIC) correspondem a todas as tecnologias que mediam os processos informacionais e comunicativos, sendo um conjunto de recursos tecnológicos utilizados pelo homem na sociedade, que se constituem de diferentes formas como: computadores, softwares, hardwares, celulares, tablets, internet, televisão, rádio, entre outras. Por conta das mudanças sociais e da utilização das TIC no cotidiano da vida das pessoas e na sociedade, as mais diversas profissões necessitam de profissionais capacitados para utilizarem diferentes tecnologias em seus contextos profissionais. Para que isso aconteça, é necessário que as instituições educacionais sejam capazes de atender ao avanço tecnológico, em especial, as universidades, sendo elas responsáveis também por formar profissionais e professores para corresponder a essa condição.

No contexto educacional, sem sombra de dúvidas, as TIC possibilitaram muitos ganhos, principalmente, no contexto da profissionalização docente. As TIC precisam estar a favor da educação diante do processo de ensino e aprendizagem, como instrumentos que possibilitam o acesso à informação para que ela possa se transformar em conhecimento. Nesta perspectiva, diante das TIC no processo de formação de professores, é importante destacar que as tecnologias proporcionaram oportunidade de formação inicial e continuada a distância, sendo que a Educação a Distância, promove o processo de ensino e aprendizagem mediado pela utilização de tecnologias digitais, onde professores e alunos estão em tempo e espaço geográfico diferenciado. A Educação a Distância, apresenta diferentes formatos, entre eles a Educação Online, Aberta, Híbrida, Massiva, dentre outros.

A Educação a Distância no formato Online é muito utilizada atualmente no processo de formação de professores, pois este modelo de processo de ensino e aprendizagem permite que ações educativas sejam desenvolvidas por meio da internet com a utilização de computadores, que permitem o acesso a um ambiente virtual de aprendizagem. Moran (2012, p. 41) enfatiza que a Educação Online é definida “como o conjunto de ações de ensino-aprendizagem desenvolvidas por meio de meios telemáticos, como a Internet, a videoconferência e a teleconferência”. Em consonância com Moran (2012), Santos (2009, p. 5663-5664) define a Educação Online como o “conjunto de ações de ensino-aprendizagem ou atos de currículo mediados por interfaces digitais que potencializam práticas comunicacionais interativas e hipertextuais". Desta maneira, entende-se que a Educação Online possibilita que a formação inicial ou continuada de professores ocorra a partir do uso de diferentes TIC, 
como celulares e computadores, que proporcionam o acesso ubíquo a cursos Online que utilizam tecnologias e plataformas em rede para que ocorra o processo de ensino e aprendizagem mediado por professores-tutores que realizam a mediação pedagógica.

$\mathrm{Na}$ Educação Online é importante que o formador de professores considere o perfil dos alunos e a evolução dos mesmos diante das TIC. Em relação à formação de professores mediada pelas TIC, cabe mencionar que a Lei de Diretrizes e Bases da Educação Nacional (LDBEN/9394/96) enfatiza no seu Art. 62 que a formação inicial e continuada para professores poderá ser realizada com o uso de recursos e tecnologias da Educação a Distância. Além disso, a LDBEN/9394/96 ressalta ainda em seu Art. 80 que “o Poder Público incentivará o desenvolvimento e a veiculação de programas de ensino a distância, em todos os níveis e modalidades de ensino, e de educação continuada". A partir de 2009, o inciso primeiro do Art. 62 desta lei possibilitou um aumento expressivo no número de matrículas para os cursos a distância, especialmente no formato Online.

Atualmente, a busca por este formato de ensino é grande, principalmente, por professores que buscam por formação continuada. A Educação Online na formação de professores é complexa, assim como no ensino presencial, o ensino é bem diferente da prática da sala de aula, tendo o professor-tutor o papel de mediador, motivador, moderador do processo de ensino. Neste sentido, Kearsley $(2011$, p. 81) afirma que "o papel mais importante do professor em classes online é assegurar alto grau de interatividade e participação, o que significa elaborar e conduzir atividades de aprendizagem que resultem em envolvimento com a disciplina e com os colegas". Outro fator fundamental para a Educação Online é a mediação pedagógica que o professor-tutor realiza no curso Online. Ele precisa compreender que os alunos aprendem de diferentes formas, por isso é importante que o docente interaja e utilize vários recursos didáticos e tecnológicos para ensinar.

Nesta perspectiva, Kearsley (2011, p. 82) faz recomendações para o processo de interação na Educação Online e destaca que "a interação entre alunos pode ser intensificada por meio de atividades de avaliação entre pares e atividades em grupo". Essas atividades, segundo Kearsley (2011, p. 82), “em um curso sem notas ou com participantes voluntários (por exemplo, um workshop interno), interatividade e participação dependerão principalmente da utilidade e da pertinência dessas atividades para os alunos". Kearsley (2011) enfatiza que quanto mais aplicáveis e interessantes forem as atividades à realidade dos alunos, maior será o nível de participação, sem 
demandar a necessidade de motivação extrínseca. É pertinente mencionar também que a participação e a interação são ações importantes para a Educação Online, posto que essas estão intimamente relacionadas, mas não são a mesma coisa. De acordo com Kearsley $(2011$, p. 82) a participação diz respeito "ao envolvimento e à presença, sem necessidade de resposta ou feedback. Por exemplo, muitos estudantes podem participar de conferências em tempo real, mesmo que apenas alguns possam realmente interagir". Já a interação é vista como trocas conversacionais em formato de diálogos entre aluno e professor ou demais alunos e o conteúdo do curso. Neste caso, Kearsley (2011, p. 82) ressalta que "o diálogo com o conteúdo significa que o sistema responde à contribuição ou às escolhas do aluno - por exemplo, respondendo a uma pergunta ou a uma busca".

Diante do exposto, compreende-se que na Educação Online, o aprendiz precisa ter a capacidade de aprender no contexto virtual e estar motivado para aprender sozinho, bem como organizar sua rotina de estudos para poder acompanhar as atividades propostas. A relação no processo de ensino e aprendizagem que acontece neste formato de Educação a Distância deve ser mútua, pois o professor-tutor e o aluno desempenham papéis importantes para que ela aconteça. A seguir, aborda-se o que se entende por Educação não formal em ambiente hospitalar.

\section{EDUCAÇÃO NÃO FORMAL EM AMBIENTE HOSPITALAR}

A educação que acontece além dos muros da escola, denominada de Educação não Formal, cresce a cada dia a partir das necessidades impostas pela sociedade por ser um tipo de educação que atende às demandas específicas do educando. A Educação não Formal apresenta-se como complexa, pois os alunos estão em diferentes ambientes de aprendizagem, permitindo assim, a inclusão e a democratização da educação para todos. Libâneo (2010, p. 30) enfatiza que a educação é: “[...] o conjunto das ações, processos, influências, estruturas, que intervêm no desenvolvimento humano de indivíduos e grupos na sua relação ativa com o meio natural e social, num determinado contexto de relações entre grupos e classes sociais". A educação é fundamental para que o ser humano possa viver em sociedade, pois é por meio dos processos educativos que o homem estabelece a sua relação com o mundo, permitindo assim seu progresso.

Na perspectiva de Libâneo (2010, p. 31), a educação pode acontecer de maneira informal, não formal e formal, sendo que cada uma dessas apresenta suas características específicas, a saber: (a) Educação informal: relativa a ações e influências exercidas no 
meio sociocultural, local em que concretizam-se as relações entre indivíduos e grupos com um determinado "ambiente humano, social, ecológico, físico e cultural, das quais resultam conhecimentos, experiências, práticas, mas que não estão ligadas, especificamente, a uma instituição, nem são intencionais e organizadas”. Ainda neste tocante, Libâneo (2010, p. 31) define que "a educação não-formal seria a realizada em instituições educativas fora dos marcos institucionais, mas com certo grau de sistematização e estruturação. Já "a educação formal compreenderia instâncias de formação, escolares ou não, onde há objetivos educativos explícitos e uma ação intencional institucionalizada, estruturada, sistemática".

Frente às definições propostas por Libâneo (2010), depreende-se que a educação não formal pode ocorrer em diferentes ambientes, tais como em um hospital, na residência do aluno, nas ONGs, nas empresas e demais espaços, além da instituição escolar, que sistematizam o processo de ensino e aprendizagem. Quando a educação não formal ocorre, por exemplo, no ambiente hospitalar, o professor precisa ter conhecimento e formação adequada para ensinar neste contexto e sua "ação pedagógica, em ambientes e condições diferenciadas, como é o hospital, representa um universo de possibilidades para o desenvolvimento e ampliação de habilidades" (MATOS; MUGIATTI, 2008, p. 116).

No ambiente hospitalar a atuação do professor pode acontecer em diversos espaços como: o ambulatório, enfermarias, brinquedoteca hospitalar, leitos de isolamento e demais ambientes construídos para a atividade educativa que estejam dentro do hospital. Segundo a Constituição Federativa de 1988, a educação é um direito de todos e enquanto "dever do Estado e da família, será promovida e incentivada com a colaboração da sociedade, visando ao pleno desenvolvimento da pessoa, seu preparo para o exercício da cidadania e sua qualificação para o trabalho" (BRASIL, 1988). Nesta perspectiva, é dever do Estado e da família promover meios para que alunos enfermos, em idade escolar e impossibilitados de frequentar suas escolas, devido a estarem internados em hospitais, para fins de tratamento médico prolongado, recebam o acompanhamento de professores capacitados, que possibilitem a continuidade do processo de escolarização, outrora realizado na escola. Ainda acerca da Constituição Federal de 1988, o capítulo II, dos Direitos Sociais, menciona o artigo 6, da seguinte maneira: "São direitos sociais a educação, a saúde, o trabalho, a moradia, o lazer, a segurança, a previdência social, a proteção à maternidade e à infância, a assistência aos desamparados [...]” (BRASIL, 1988, grifo dos autores). 
Diante das políticas públicas da educação, o Plano Nacional de Educação (PNE) 2014-2024 tem como uma das metas a "universalização do atendimento escolar" (BRASIL, 2014), sendo a escolarização no ambiente hospitalar uma forma de universalizar a educação aos alunos que estão afastados da educação formal por estarem hospitalizados. Se por um lado o PNE visa à expansão da escolarização, o Estatuto da Criança e do Adolescente (ECA), lei nº 8.069 de 13 de junho de 1990, por sua vez, dispõe de garantias ao direito para crianças e adolescentes à saúde e à continuidade de sua escolarização. Complementarmente, as Diretrizes Nacionais para a Educação Especial na Educação Básica - Resolução CNE/CEB n 2, de 11 de Setembro de 2001, reafirmam esse direito:

Art. 13. Os sistemas de ensino, mediante ação integrada com os sistemas de saúde, devem organizar o atendimento educacional especializado a alunos impossibilitados de frequentar as aulas em razão de tratamento de saúde que implique internação hospitalar, atendimento ambulatorial ou permanência prolongada em domicílio (BRASIL, 2001).

As Diretrizes Nacionais para a Educação Especial na Educação Básica Resolução CNE/CEB n 2, de 11 de Setembro de 2001 expressam a preocupação com a escolarização no ambiente hospitalar, mas deixam claro que a educação no ambiente hospitalar é destinada os alunos da educação especial. No contexto brasileiro, atualmente, a Educação Especial apresentou mudanças com novos direcionamentos para essa modalidade de ensino. Antes do ano 2000, as leis e resoluções das políticas educacionais não mencionavam e nem orientavam sobre o processo de educação no ambiente hospitalar, mas a partir das Diretrizes Nacionais para a Educação Especial na Educação Básica de 2001 e das Diretrizes Operacionais para o Atendimento Educacional Especializado na Educação Básica, modalidade Educação Especial de 2009 assegurou-se a garantia à educação não formal no ambiente hospitalar aos alunos da educação especial. No entanto, as referidas diretrizes não mencionam esse tipo de educação aos alunos da educação básica.

Até o momento, não existe outro documento legal que esclareça essa forma de educação não formal aos alunos, diante da educação básica nos seus diferentes níveis e modalidades de educação e ensino. Diante deste panorama, que apresentou uma série de leis que asseguram garantias para que os alunos possam dar continuidade ao processo de escolarização no ambiente hospitalar, convém ressaltar que no Brasil a educação não 
formal que ocorre dentro do hospital é pouco conhecida, pela sociedade e pelos professores. Alguns estados e municípios brasileiros possuem legislação própria à nível estadual e municipal, garantindo aos alunos hospitalizados o direito de dar continuidade aos seus estudos, todavia essa garantia depende das políticas públicas das esferas mencionadas, que podem viabilizar ou não a continuidade a esse direito.

No contexto acadêmico, a educação não formal que ocorre no ambiente hospitalar recebe muitas denominações, a saber: Pedagogia Hospitalar, Atendimento Pedagógico ao escolar em tratamento de saúde, Classe Hospitalar, entre outras, que variam de acordo com as políticas públicas municipais e estaduais. Ainda, não existe uma denominação e um conceito formado pelos pesquisadores que investigam essa temática, pois não há uma legislação nacional específica que estabeleça diretrizes e orientações aos estados e aos municípios, quanto a como realizar essa educação. A educação não formal que acontece no ambiente hospitalar contribui para a redução do tempo de internação, para o bem-estar físico e psíquico do aluno e, principalmente, para a continuidade do processo de escolarização, que irá permitir que o aluno retorne à escola para receber a educação formal.

Contudo, o processo de hospitalização não é fácil, muitas dificuldades podem ser vividas durante o período de internação, mas estar internado em um hospital não priva o direito à continuidade à educação, principalmente quando a equipe de profissionais da saúde, entre eles, o médico, libera o aluno para que o mesmo receba o atendimento pedagógico dentro do hospital. Vários pesquisadores, como Simancas e Lorente (1990), Matos (2009), Ferreira, (2013), Matos e Ferreira (2015) e Ferreira e Behrens (2016) desenvolveram pesquisas sobre a educação não formal em contexto hospitalar e identificaram significativas contribuições do processo de ensino e aprendizagem para a recuperação do aluno. Na próxima seção, apresenta-se a metodologia de pesquisa.

\section{METODOLOGIA}

Esta é uma pesquisa qualitativa de natureza interpretativa do tipo exploratória, conquanto o objetivo de uma pesquisa de metodologia exploratória é o de familiarizarse com um assunto ainda pouco conhecido ou pouco explorado, como é o caso da educação não formal realizada em ambiente hospitalar. Bogdan e Biklen (1994) afirmam que a pesquisa qualitativa apresenta características que são essenciais a 
abordagem exploratória, sendo essas: a) a fonte de dados é o ambiente natural para esta abordagem de investigação; b) é fortemente descritiva; c) os pesquisadores focam os resultados a partir do processo e não somente a partir dos resultados encontrados; d) os dados são analisados de forma indutiva e; e) os pesquisadores que utilizam essa abordagem estão interessados também na diversidade de opiniões sobre o fenômeno investigado.

A presente pesquisa contou com a participação de 178 professores de diversos estados brasileiros, atuantes em ambiente hospitalar, os quais responderam a um questionário Online após participarem do curso de extensão Online, via ambiente virtual de aprendizagem (AVA) Eureka da Pontifícia Universidade Católica do Paraná (PUCPR). Como mencionado na introdução deste estudo, o curso em questão é derivado de projeto de pesquisa aprovado pelo Conselho Nacional de Desenvolvimento Científico e Tecnológico (CNPq) e pelo Comitê de Ética em Pesquisa (CEP) da PUCPR, sob o parecer $n^{\circ} 852.829$.

A coleta de dados ocorreu por meio de um questionário formativo enviado por e-mail para os 178 professores que concluíram o curso de extensão Online, dentre eles aprovados e reprovados. Todos os professores participantes do curso aceitaram responder o questionário Online, assim como, por meio de uma janela digital do tipo pop-up, tiveram acesso ao Termo de Consentimento Livre e Esclarecido (TCLE) e informações complementares a respeito desta pesquisa. Para tanto, o corpus de pesquisa constituiu-se a partir da análise de 178 respostas relacionadas, especificamente à pergunta de número quatro, na qual questionava-se: Quais foram as suas dificuldades para realizar o curso de extensão Online ofertado? A análise dos dados coletados por meio do questionário Online foi realizada com o auxílio do software Atlas Ti, assim como a partir da Análise de Conteúdo (AC) proposta por Bardin (2011).

A técnica de AC é, geralmente, utilizada para a análise de dados textuais, imagens, gravações, dentre outros, sendo ela um método de pesquisa comumente usado pelas Ciências Sociais, Psicologia e Educação. De acordo com Bardin (2011), a AC é constituída por um conjunto de técnicas de análise, que adota procedimentos sistemáticos para a descrição do conteúdo de mensagens. A AC contempla diferentes etapas do processo de análise, não se configurando como uma técnica isolada de análise, aspecto que permite que cada pesquisador utilize-a de acordo com o entendimento que possui acerca de seu objeto de estudo. Ainda neste horizonte, Bardin (2011) afirma que a AC é constituída por três fases, sendo essas: (a) pré-análise, (b) 
exploração do material e (c) tratamento dos resultados. As etapas mencionadas foram adotadas neste estudo para fins de análise de dados. A seguir, apresenta-se, uma breve contextualização do curso de extensão Online, que serviu como campo de coleta de dados para a realização da pesquisa aqui apresentada.

\section{FORMAÇÃO CONTINUADA ONLINE: O CURSO DE EXTENSÃO}

A seleção dos docentes para participação no curso "Eureka - Ambiente Virtual favorecendo a formação continuada Online para professores que atuam com escolares hospitalizados", via ambiente virtual de aprendizagem (AVA) Eureka da Pontifícia Universidade Católica do Paraná (PUCPR) ocorreu a partir de um questionário diagnóstico, que fazia parte de um informativo de divulgação do curso de extensão Online, que foi divulgado nas redes sociais. Após a divulgação do curso, registrou-se um total de 549 professores inscritos, enquanto candidatos, porém apenas 178 foram selecionados, tendo em vista que 371 professores inscritos não atuavam como docentes em hospitais. No entanto, convém observar que mesmo que até mesmo os candidatos que não se enquadravam no perfil do curso haviam manifestado interesse em participar da formação continuada, com vistas a obter conhecimentos sobre o assunto do curso.

Relativo aos 178 professores, efetivamente, participantes do curso, 60\% tinham faixa etária entre 33 a 50 anos, $75 \%$ possuíam vínculo empregatício em secretarias estaduais e municipais de educação; 60\% eram do Estado do Paraná e de outros Estados como Bahia, Minas Gerais, Pará, Rio de Janeiro, Rio Grande do Sul e São Paulo; 55\% tinham de 7 a 10 anos de atuação profissional como professores de ambiente hospitalar; e $96 \%$ apresentavam especialização e $4 \%$ mestrado, como nível de escolarização. Os professores relataram lecionar em diversas áreas (licenciaturas), sendo alguns pedagogos, atuantes em diferentes níveis e modalidades de educação e ensino na educação não formal, especificamente, voltada ao ambiente hospitalar. O curso extensão ocorreu em cinco salas virtuais no AVA Eureka, tendo essas em média 35 participantes e dois professores-tutores para mediar o processo de ensino $\mathrm{e}$ aprendizagem. O curso foi planejado e desenvolvido, especificamente, para professores atuantes em ambiente hospitalar, tendo este sido composto por 12 unidades, sendo que cada unidade foi planejada a partir das necessidades de formação que os docentes apontaram no questionário diagnóstico que responderam, previamente, ao ingresso no curso. 
As unidades do curso e objetivos se dividiram em: Unidade 01 - "Informações Básicas do Curso de Extensão"; Unidade 02 - "Fórum de Ambientação e Integração"; Unidade 03 - “Atendimento Pedagógico Educacional do escolar em tratamento de saúde"; Unidade 04 - "Políticas Públicas Educacionais voltadas ao escolar em tratamento de saúde"; Unidade 05 - "Mudança de Paradigma na Educação e na Saúde"; Unidade 06 - "Educação e Saúde: cuidados básicos do professor no ambiente hospitalar"; Unidade 07 - "Escolarização Hospitalar"; Unidade 08 - "Atendimento Pedagógico Domiciliar"; Unidade 09 - "Contação de Histórias"; Unidade 10 "Linguagens Múltiplas"; Unidade 11 - "Portfólio Digital"; e Unidade 12 - "Seminário Final". Cada unidade do curso de extensão Online permitiu que os professores tivessem conhecimentos sobre diferentes teorias e práticas pedagógicas, a utilização de vários recursos didáticos e pedagógicos, bem como, a apropriação de conhecimentos que fossem significativos para a prática docente na realidade hospitalar.

Em cada unidade desenvolvida foi disponibilizado aos professores diversos materiais em vários formatos, como artigos, vídeos, informativos, desenhos, questionários, entre outros e um e-book, que apresentava todos os conteúdos trabalhados no curso. Ao final do curso foi fornecido certificado de participação para os professores que realizaram $70 \%$ das atividades desenvolvidas em cada unidade, assim como a postagem do portfólio digital (unidade 12) no AVA Eureka. Dos professores participantes 123 foram aprovados e 55 reprovados. Aborda-se, na próxima seção, a análise de dados e os resultados obtidos.

\section{ANÁLISE DE DADOS E RESULTADOS}

Relativo à análise de dados das 178 respostas da pergunta 4 do questionário formativo, a seguir, descreve-se a aplicação de cada etapa, preparação dos dados para análise (pré-análise), utilização do software Atlas Ti, codificação, categorização (exploração do material) e análise de conteúdo (tratamento dos resultados), a saber:

Fase 1 - Preparação dos dados para análise: todas as 178 respostas dos questionários foram salvas em formato PDF e inseridas no software Atlas Ti, recebendo, por conseguinte, um código para cada resposta, preservando o anonimato dos participantes. Desta forma, as respostas receberam o seguinte código RP102S4 que significa, R- Resposta, P- Participante, 102- número do participante e S4- sala 4. Todos os códigos elaborados foram registrados em uma planilha de Excel, contendo: nome 
completo do participante e sala que os mesmos estavam inseridos e as respostas de cada pergunta.

Fase 2 - Exploração do material: As 178 respostas foram selecionadas pelos pesquisadores no software Atlas Ti, com a finalidade de que essas fossem, em seguidas, codificadas com o auxílio da referida ferramenta computacional.

Fase 3 - Codificação: Nesta etapa foram criados códigos, a fim de operacionalizar o processo de categorização. Os códigos são representados por um sistema de símbolos que permite a identificação de informações. A posteriori, realizouse uma leitura crítica das respostas selecionados, criando para essas, códigos que expressam dificuldades ou implicações para realizar o curso de extensão online. Conforme acontecia a leitura das respostas os pesquisadores utilizaram também códigos já previamente criados. Para as respostas da pergunta 4 do questionário formativo foram criados 29 códigos.

Fase 4 - Categorização: Nesta etapa visou-se à união, ou seja, à formação de conjuntos de códigos por incidência e semelhança, ação que permite agrupar dados e consolidar um significado para tais informações. Depois que todas as respostas foram codificadas e categorizadas visualizou-se no software Atlas Ti os códigos que tiveram maior incidência e semelhança.

Fase 5 - Análise de Conteúdo: Os códigos com maior incidência e semelhança foram submetidos a quatro procedimentos adicionais, por meio da Análise de Conteúdo (BARDIN, 2011), sendo esses: a) leitura detalhada dos resultados encontrados; b) análise reflexiva, por parte dos pesquisadores, das respostas das perguntas; c) identificação e criação dos grupos de categorias de convergência, para fins de consolidação de um significado; e d) criação de categorias de significados.

As categorias emergentes constituíram-se como indicadores, as quais possibilitaram compreender as incidências semelhantes presentes nas respostas dos participantes permitindo que os pesquisadores pudessem identificar as dificuldades dos participantes para realizar o curso de extensão Online. A seguir, no Quadro 1, apresenta-se três elementos textuais identificados nas respostas dos participantes, que foram utilizados como exemplos para a criação das categorias, diante da quantidade de incidência e de semelhança que um mesmo código teve. Diante da análise dos dados, o software Atlas Ti revelou 02 códigos que tiveram maior incidência e semelhança frente aos resultados analisados que abordavam os seguintes aspectos: a) a falta de tempo, b) dificuldade para atuar como aluno Online. Como mencionado, um dos códigos que 
apresentou incidência e semelhança nas respostas dos professores foi a "falta de tempo", com 126 incidências. Conforme o Quadro 01, apresenta-se as categorias que foram criadas a partir do código analisado.

Quadro 1: Categoria Falta de Tempo e incidências por código

\begin{tabular}{|c|c|}
\hline CATEGORIAS & PARTICIPANTE \\
\hline \multicolumn{2}{|l|}{ FALTA DE TEMPO } \\
\hline Excesso de atividades realizadas na docência & $\begin{array}{l}\text { Quantidade } \\
\text { incidência } \\
\text { código: } 72\end{array}$ \\
\hline $\begin{array}{l}\text { Sou professora regente no período da tarde em uma escola particular e no } \\
\text { período da manhã atuo como professora em um hospital especializado no } \\
\text { atendimento de crianças e adolescentes. A minha maior dificuldade para } \\
\text { realizar o curso online foi devido a minha falta de tempo para estudar e } \\
\text { realizar as atividades propostas. As minhas atividades como professora da } \\
\text { escola particular tomam muito do meu tempo, principalmente para } \\
\text { preparar as aulas e realizar as atividades propostas pela escola. }\end{array}$ & RPO6S1 \\
\hline $\begin{array}{l}\text { O curso realizado no meu ponto de vista foi muito bom, atendeu as minhas } \\
\text { expectativas, pena que não pude acompanhar como eu gostaria. A minha } \\
\text { falta de tempo foi a minha maior dificuldade para ler e realizar as } \\
\text { atividades do curso. Atuo como professora nos } 3 \text { turnos e no final de } \\
\text { semana me dedico para fazer as atividades que não consegui realizar na } \\
\text { escola. }\end{array}$ & RP89S4 \\
\hline $\begin{array}{l}\text { Minha maior dificuldade está em relação a minha falta de tempo para } \\
\text { acompanhar e me dedicar ao curso. A minha falta de tempo está } \\
\text { relacionada as minhas atribuições como professora, são cansativas. }\end{array}$ & RP37S2 \\
\hline Cuidado com a família & $\begin{array}{l}\text { Quantidade } \\
\text { incidência } \\
\text { código: } 33\end{array}$ \\
\hline $\begin{array}{l}\text { Tive dificuldades para acompanhar o curso porque não organizei meu } \\
\text { tempo para estudar, fiquei alguns finais de semana dando atenção a minha } \\
\text { família. }\end{array}$ & RP45S5 \\
\hline $\begin{array}{l}\text { Me falou tempo para estudar e interagir diante do curso, tive que dar } \\
\text { atenção para o meu filho nos finais de semana, pois meu marido viajou a } \\
\text { serviço. }\end{array}$ & RP148S3 \\
\hline $\begin{array}{l}\text { A minha dificuldade está relacionada a falta de tempo para me dedicar ao } \\
\text { curso, a formação realizada por vocês foi muito boa, mas pequei nesse } \\
\text { quesito, tive que dar atenção aos meus filhos e marido }\end{array}$ & RP111S4 \\
\hline Desorganização pessoal & $\begin{array}{l}\text { Quantidade } \\
\text { incidências } \\
\text { código: } 21\end{array}$ \\
\hline $\begin{array}{l}\text { Tive grande dificuldade para realizar as atividades propostas no tempo } \\
\text { certo, sou desorganizado. }\end{array}$ & RP77S1 \\
\hline $\begin{array}{l}\text { A minha desorganização para realizar o curso online contribuiu para que } \\
\text { eu não tivesse tempo suficiente para cumprir os prazos determinados. }\end{array}$ & RP28S3 \\
\hline $\begin{array}{l}\text { A minha falta de tempo atrelada a minha desorganização dificultou o meu } \\
\text { rendimento no curso. Esse foi o primeiro curso que realizei a distância, } \\
\text { para os próximos cursos vou procurar ser mais organizada. }\end{array}$ & RP100S5 \\
\hline
\end{tabular}

Fonte: Autores 
No quadro 01, foi possível identificar que o código "excesso de atividades realizadas na docência" apresentou 72 incidências, sendo uma categoria que evidenciou a sobrecarga de trabalho que envolve a docência. As atribuições do trabalho docente contribuíram para que os professores não tivessem um tempo mínimo para realizar a formação continuada Online. De uma maneira geral, os professores brasileiros, tanto da educação formal, quanto da educação não formal, tendem a trabalhar em até 3 turnos, em diferentes escolas, em vários contextos além dos muros da escola (DUARTE, 2008; OLIVEIRA, 2006). Portanto, conciliar a atividade docente em hospitais e instituições de ensino regular deixa evidente a realidade vivenciada por professores que atuam em contextos distintos, porém ambos focados no processo educacional. Relativo às jornadas intensas e extensas assumidas pelos professores, Esteves (1995) cita a expressão "mal-estar docente" que é relativa aos efeitos negativos de uma atuação profissional com sobrecarga, que pode levar os professores a não se sentirem aptos ao exercício da docência ao longo do tempo.

Ainda neste tocante, Monlevade (2000) reitera que jornadas com sobrecarga de atividades docentes, em geral, dificultam o acesso à formação continuada por parte dos professores, muito embora esses necessitem de tempo para "realimentação profissional". Para além da categoria mencionada, constatou-se referência ao "cuidado com a família" e à "desorganização pessoal” como categorias citadas pelos professores, sendo esses fatores que influenciaram negativamente o processo de formação continuada Online.

Conforme mencionado, outro código que identificado como de maior incidência e semelhança nas respostas dos professores refere-se à a dificuldade "para atuar como aluno Online". Este código revelou 144 incidências, as quais são referentes à interação e à motivação durante a realização o do curso de extensão Online. No Quadro 02 é possível identificar as categorias que foram criadas a partir do código analisado. 
Quadro 2: Categoria Dificuldade para atuar como aluno online e incidências por código

\begin{tabular}{|c|c|}
\hline CATEGORIAS & PARTICIPANTE \\
\hline \multicolumn{2}{|l|}{ DIFICULDADE PARA ATUAR COMO ALUNO ONLINE } \\
\hline Interação & $\begin{array}{ll}\text { Quantidade } & \text { de } \\
\text { incidência } & \text { do } \\
\text { código: } 89 & \end{array}$ \\
\hline $\begin{array}{l}\text { Tive dificuldade para atuar como aluno online, estou acostumado a ser } \\
\text { professor e aluno no presencial. Mesmo sendo professor tive grandes } \\
\text { dificuldades para interagir com o professor-tutor e os demais professores } \\
\text { que fizeram o curso. }\end{array}$ & RP13S1 \\
\hline $\begin{array}{l}\text { Atuar como aluna online não foi fácil, ainda mais para interagir e me } \\
\text { motivar a participar das atividades. }\end{array}$ & RP88S2 \\
\hline $\begin{array}{l}\text { A minha maior dificuldade está relacionada a me portar como aluna da } \\
\text { EAD, não foi fácil, estudar a distância querer comprometimento. Interagi } \\
\text { muito pouco com os colegas, perdi a oportunidade que conhecer outros } \\
\text { professores que realizam a mesma atividade que eu realizo. }\end{array}$ & RP166S3 \\
\hline Minha motivação & $\begin{array}{l}\text { Quantidade de } \\
\text { incidência que o } \\
\text { código teve: } 55\end{array}$ \\
\hline $\begin{array}{l}\text { Me portar como aluna online foi bastante complicado, muitas vezes não } \\
\text { tinha motivação pessoal para realizar o curso. }\end{array}$ & RP50S5 \\
\hline $\begin{array}{l}\text { Fazer um curso a distância não é fácil, requer disciplina e autonomia. Eu } \\
\text { tive muita dificuldade para atuar virtualmente, principalmente no quesito } \\
\text { motivação para realizar algumas atividades que foram propostas. }\end{array}$ & RP10S4 \\
\hline $\begin{array}{l}\text { Não tinha motivação para realizar algumas atividades que foram propostas. } \\
\text { A minha atuação como aluna da educação a distância deixou a desejar. }\end{array}$ & RP177S3 \\
\hline
\end{tabular}

Fonte: Autores

No quadro 02, é possível verificar que o código "dificuldade para interagir como aluno online" apresentou 89 incidências, sendo uma categoria que reforça a dificuldade dos alunos interagirem em um curso Online, no qual o aluno precisa exercitar trocas comunicacionais via AVA com colegas e professor. Neste sentido, a interação precisa ocorrer do ingresso no curso até sua finalização, isso porque o aluno precisa ambientarse com o espaço digital em que está inserido, bem como com os demais indivíduos que ali então para trocar e adquirir conhecimentos acerca de um determinado assunto. A dificuldade em interagir Online, no caso do curso em questão, pode também estar associada ao fato de que os professores interessados em adquirir formação continuada, voltada à atuação em hospitais, como mencionado na seção de metodologia, tinham recebido formação em nível superior em um período em que as TIC não estavam tão 
presentes no cenário de formação de professores. Neste horizonte, infere-se que a condição de imigrantes digitais (PRENSKY, 2001) possa ter reforçado a dificuldade em consolidar interações consistentes, a fim de estabelecer um real sentimento de pertencimento ao ambiente digital e ao grupo como um todo.

A categoria "minha motivação", como incidência de 55 códigos, pareceu reiterar a realidade docente no Brasil, posto que, conforme mencionado na análise do Quadro 1, identificou-se que os professores que atuam em ambiente hospitalar possuem dupla jornada de trabalho, o que sugere cansaço e desmotivação, posto que trabalham em contexto de Educação não Formal e Formal, o que corrobora as postulações de autores como Duarte (2008), Oliveira (2006), Esteves (1995) e Monlevade (2000) quanto à caracterização do perfil dos docentes brasileiros. Nesta categoria, os professores enfatizaram que a falta de motivação para realizar as tarefas do curso podem ter se originado da não familiaridade com o contexto educacional Online, assim como pela desorganização pessoal. Na próxima seção, são apresentas as considerações finais.

\section{CONSIDERAÇÕES FINAIS}

Diante da realização desta pesquisa, voltada às dificuldades enfrentadas por professores da Educação não Formal, que atuam em ambiente hospitalar, quando da participação em um curso de extensão Online, depreende-se, inicialmente, a necessidade de uma legislação específica e nacionalmente regulamentada, relativa à atividade profissional destes docentes. Esta inferência não apenas diz respeito ao fato de que esses professores atuam em contextos não formais, os quais podem ser mais desafiadores para o exercício da atividade docente, mas, também com vistas a assegurar que esses tenham condições de se "realimentarem" profissionalmente, conforme mencionado neste artigo. Além disso, a constatação de dificuldades permite que o planejamento e o desenvolvido de cursos de extensão Online, na modalidade de Educação a Distância, possam ser repensados, tendo em vista o perfil dos professores que buscam formação continuada direcionada à atividade docente em ambientes hospitalares. Cabe ressaltar, que, como referido na metodologia desta pesquisa, a procura pelo curso em questão revelou o significativo interesse dos profissionais da educação a respeito da temática, até mesmo por parte daqueles que ainda não atuam em ambiente hospitalar. Neste sentido, entende-se a latente necessidade de oferta de cursos de mesma temática, a fim de proporcionar formação continuada neste segmento. 
Concernente à participação no curso, depreendeu-se que as atividades propostas aos professores, considerando o perfil dos mesmos, devem possuir maior prazo para realização, a fim de que esses possam conciliar a dupla jornada, na educação formal e não formal, com a participação em uma formação continuada a distância.

Relativo às categorias apresentadas na seção de análise de dados, infere-se que as dificuldades manifestadas pelos professores indicam que esses, embora ávidos por formação continuada, mesmo frente à jornada intensa e extensa de trabalho, carecem de maior tempo de ambientação em um AVA. Esse entendimento está sustentado e corroborado a partir das categorias de "falta de tempo" e "dificuldade para interagir como aluno online" identificadas e apresentadas como emergentes a partir da participação dos professores no curso de formação continuada. Diante desta perspectiva, se por um lado a Educação a Distância tem se mostrado válida para a formação continuada Online, por outro, constatou-se que o perfil do participante, professores atuantes em ambiente hospitalar, é um aspecto que deve ser levado em consideração, a fim de que o design do curso efetivamente contemple as necessidades destes profissionais.

Diante do exposto, considera-se que a Educação a Distância representa a possibilidade de oferta de formação continuada a professores que procuram formas de aprimoramento de suas práticas profisssionais instauradas na educação não formal. As dificuldades, em geral, presentes em todo e qualquer processo formativo, apenas ilustram que é preciso familiarizar-se com os AVAs e interagir de maneira representativa para que o processo de aprendizagem ocorra de modo a gerar conhecimento sobre um determinado tema.

\section{REFERÊNCIAS}

BARDIN, Laurence. Análise de Conteúdo. São Paulo: Edições 70, 2011.

BOGDAN, Robert C; BIKLEN, Sari Knopp. Investigação Qualitativa em Educação. Porto: Editora Porto, 1994.

BRANDÃO, Carlos Rodrigues. O que é Educação. 49. ed. São Paulo: Brasiliense, 2007.

BRASIL. Constituição da República Federativa do Brasil. Brasília: Imprensa Oficial, $1988 . \quad$ Disponível em: $<$ http://www.planalto.gov.br/ccivilconstituicao/constituicao.htm $>$. Acesso em: 06. Jan. 2018. 
BRASIL. Estatuto da Criança e o Adolescente. Lei no 8.069/90 de 13 de julho de 1990. Diário Oficial da União, Brasília, DF: Imprensa Oficial, 1990. Disponível em: < http://www.planalto.gov.br/ccivil_03/leis/18069.htm>. Acesso em: 06. Jan. 2018.

BRASIL. Lei de Diretrizes e Bases da Educação Nacional. Lei no 9.394, de 20 de Dezembro de 1996. Estabelece as diretrizes e bases da educação nacional. Diário Oficial da União, Brasília, DF, 23 dez. 1996. Disponível em: $<$ http://www.planalto.gov.br/ccivil_03/leis/19394.htm>. Acesso em: 09. Jan. 2018.

BRASIL. Ministério da Educação. Conselho Nacional de Educação/Câmara de Educação Básica. Resolução n $^{\circ} 2$ de 11 de Setembro de 2001. Brasília: MEC, 2001. Institui as Diretrizes Nacionais para a Educação Especial para a Educação Básica. Disponível em: <http://portal.mec.gov.br/cne/arquivos/pdf/CEB0201.pdf>. Acesso em: 15. Jan. 2018.

BRASIL. Plano Nacional de Educação - PNE. Lei no 13.005, de 25 de junho de 2014. Diário Oficial da União, Brasília, DF, 25 jun. 2014. Disponível em: $<$ http://www.planalto.gov.br/CCIVIL_03/_Ato2011-2014/2014/Lei/L13005.htm>. Acesso em: 06. Jan. 2018.

DUARTE, Adriana M. C. O trabalho docente na educação básica: novas configurações e formulações teórico conceituais. In: Seminário da Rede LatinoAmericana de Estudos sobre Trabalho Docente- Rede Estrado, 7., 2008, Buenos Aires. Anais. Buenos Aires: REDE ESTRADO, 2008. 1 CD-ROM.

FERREIRA, Jacques de Lima. Educação e Saúde: cuidados básicos do professor no atendimento pedagógico ao escolar em tratamento de saúde. In: MATOS, Elizete Lúcia Moreira; FERREIRA, Jacques de Lima Ferreira. Formação Pedagógica para o atendimento ao escolar em tratamento de saúde: redes de possibilidades online. Petrópolis, RJ: Vozes, 2013. p. 166-178.

FERREIRA, Jacques de Lima (Org.). Formação de Professores: teoria e prática pedagógica. Petrópolis, RJ: Vozes, 2014.

FERREIRA, Jacques de Lima; BEHRENS, Marilda Aparecida. Formação Continuada Online para Docentes que atuam no Atendimento Pedagógico ao Escolar em tratamento de Saúde. Revista da FAEEBA - Educação e Contemporaneidade, Salvador, v. 25, n. 46, p. 121-139, maio/ago. 2016. Disponível em: $<$ https://www.revistas.uneb.br/index.php/faeeba/article/view/2715>. Acesso em: 08 . Jan. 2018.

GOHN, Maria da Glória. Educação não formal e o educador social: atuação no desenvolvimento de projetos sociais. São Paulo: Cortez, 2010.

KEARSLEY, Greg. Educação Online: aprendendo e ensinando. São Paulo: Cengage Learning, 2011.

LIBÂNEO, José Carlos. Pedagogia e Pedagogos, para quê? 12. ed. São Paulo: Cortez, 2010. 
MATOS, Elizete Lúcia Moreira; MUGIATTI, Margarida Maria Teixeira de Freitas. Pedagogia Hospitalar: a humanização integrando educação e saúde. 3. ed. Petrópolis, RJ: Vozes, 2008.

MATOS, Elizete Lúcia Moreira (Org.). Escolarização Hospitalar: educação e saúde de mãos dadas para humanizar. Petrópolis, RJ: Vozes, 2009.

MATOS, Elizete Lúcia Moreira; FERREIRA, Jacques de Lima. Formação de Professores: o atendimento pedagógico ao escolar em tratamento de saúde - APETS. In: MIGUEL, Maria Elisabeth Blanck; FERREIRA, Jacques de Lima (Org.). Formação de Professores: história, políticas educacionais e práticas pedagógicas. Curitiba: Appris, 2015. p. 219-237.

MONLEVADE, João A. C. Valorização salarial dos professores: o papel do piso salarial profissional nacional como instrumento de valorização dos professores da educação básica pública. 2000. 315 f. Tese (Doutorado em Educação) - Faculdade de Educação, Universidade Estadual de Campinas, Campinas, 2000.

MORAN. José Manuel. Contribuições para uma Pedagogia da Educação Online. In: SILVA, Marco (Org.). Educação Online: teorias, práticas, legislação e formação corporativa. 4. ed. São Paulo: Edições Loyola, 2012, p. 41-52.

OLIVEIRA, Dalila A. Regulação educativa na América Latina: repercussões sobre a identidade dos trabalhadores docentes. Educação em Revista. Belo Horizonte, v. 44, p. 209-227, dez. 2006.

PRENSKY, Marc. Digital Natives, Digital Immigrants. MCB University Press, 2001.

SANTOS, Edméa. O currículo em rede e o ciberespaço como desafio para a EAD. In: ALVES, Lynn; NOVA, Cristiane. (Orgs.). Educação a distância: uma nova concepção de aprendizado e interatividade. São Paulo: Futura, 2003.

SANTOS, Edméa. Educação Online para além da EAD: um fenômeno da cibercultura. In: Actas do Congresso Internacional Galego-Português de Psicopedagogia, 10, 2009, Braga. Anais...Braga: Universidade do Minho, 2009. p. 5658-5671. Disponível em:

http://www.educacion.udc.es/grupos/gipdae/documentos/congreso/Xcongreso/pdfs/t12/t 12c427.pdf $>$. Acesso em: 04. Jan. 2018.

SILVA, Marco. Educação Online: teorias, práticas, legislação, formação corporativa. 2. ed. São Paulo: Edições Loyola, 2009.

SILVA, Marco. Formação de Professores para a Docência Online. São Paulo: Edições Loyola, 2012.

SIMANCAS, José Luis Gonzáles; LORENTE, Aquilino Polaino. Pedagogía Hospitalar: actividad educativa em ambientes clínicos. Madri: Narcea, 1990. 